\title{
CrimRxiv
}

\section{Review 1 of "Defense,}

disrespect, and \#deadly: A

qualitative exploration of

precursors to youth

violence informed through

hospital-based violence

prevention program follow

up"

Jun Sung Hong

Published on: Jun 21, 2021

License: Creative Commons Attribution 4.0 International License (CC-BY 4.0). 
Vote: Publish pending minor changes

[For votes to count, referees must reasonably explain why they voted as they did. Thus, please explain your vote. If you voted to publish pending minor changes, specify each change, why it is needed, and, possibly, how it should/could be done.]

The study can make a significant contribution to the literature on youth violence. The study would be of interest to the readers and to the practitioners especially youth workers in urban areas.

[Please put additional info below, as/if you see fit.]

I would encourage the authors to go through one more round of edits to make sure the study is free of typos, etc. 